\title{
Management of sheath blight in rice through application of Validamycin, Trichoderma harzianum and Pseudomonas fluorescence
}

\author{
Ramji Singh*1, B.P. Singh, Alka Singh, Udai Prakash Singh ${ }^{1}$ and R.S. Kureel ${ }^{2}$ \\ Department of Plant Pathology N.D. University of Agriculture and Technology Kumarganj, Faizabad (U.P.) INDIA \\ ${ }^{1}$ Department of Plant Pathology College of Agriculture SVP University of Agriculture and Technology, Meerut (U.P.), \\ INDIA \\ ${ }^{2}$ National Oilseed and Vegetable Oil Development Board, Gurgaon, INDIA \\ *Corresponding author. E-mail: singh.ramji@gmail.com
}

\begin{abstract}
Eleven different combinations of Trichoderma harzianum, Psedumonas fluorescens and Validamycin 3L, were applied at different crop stages viz. seed, seedling, tillering and symptoms initiation along with one application of Carbendazim as standard control to test their efficacy against sheath blight of rice caused by Rhizoctonia solani under field condition. One application of Carbendazim @ $0.1 \%$ at the time of symptoms initiation (with 81.36 percent reduction of disease incidence, 83.17 percent reduction in disease severity and 62.92 percent inhancement in yield) and seed treatment with Trichoderma harzianum and seedling root dipping with Pseudomonas fluorescens and two spraying of Validamycin i.e. at tillering and symptoms initiation stages (with 69.10 percent reduction of disease incidence, 83.17 percent reduction in disease severity and 62.49 percent inhancement in yield) were found to be equally and highly effective in reducing the sheath blight severity and in increasing rice grain yield also. One spraying of Validamycin at symptoms initiation stage was comparatively less effective (29.54 per cent reduction in disease incidence,53.46 per cent reduction in disease severity and 47.76 per cent enhancement in yield ) than one spraying of Carbendazim at symptoms initiation stage.
\end{abstract}

Keywords: Trichoderma harzianum, Psedumonas fluorescens, Validamycin, Sheath blight incidence, Severity, Disease management, Yield enhancement

\section{INTRODUCTION}

Rice crop is subjected to attack by many diseases caused by fungi, bacteria, viruses, nematodes and several physiological disorders, which causes annual loss to the tune of 12 to 25 per cent of the total production. Among various fungal diseases, the sheath blight caused by Rhizoctonia solani Kuhn earlier considered to be minor disease is now regarded as an internationally important disease. Now it is second only to and often rivals of blast disease. This has happens because of introduction of high yielding varieties in post green revolution era of Indian Agriculture. Sheath blight of rice is more severe in high yielding varities and favoured by application of high dosages of nitrogenous fertilizers. Weed population around the field and frequent heavy rains also creats congenial environment for heavy outbreak of this disease. Prevalence of disease occurs in almost every rice growing area of the country. Initiation of disease starts right from seedling stage but tillering and panicle initiation stages are highly prone for infection. The disease was first time reported by Miyake from Japan in the year 1910 and the fungus associated was Rhizoctonia solani. Losses of 1.2 to 69 per cent from India have been reported due to this disease. Thus, sheath blight caused by Rhizoctonia solani Kuhn is most economically important disease and has posed a challenge to the farmers for successful cultivation of rice and ultimately to the plant pathologists. Keeping this fact in view, the present investigations were, therefore, under taken to develop a suitable Integrated disease management practice for sheath blight in rice.

\section{MATERIALS AND METHODS}

The experiment was conducted using a highly susceptible variety of rice i.e. Pusa basmati-1. In total there were 13 treatments (Table -1). Each treatment was replicated three times in Randomized Block Design. To ensure heavy inoculum pressure in experimental field, the mass culture of Rhizoctonia solani was prepared using autoclaved sorghum grains and uniformly broadcasted in the field, prior to transplanting. The chemical (Validamycin)was applied @0.1 percent, while Tricoderma herzianum and Pseudomonous fluorescens were applied @ $4 \mathrm{~g} \mathrm{Kg}^{-1}$ seed for seed treatment and $10 \mathrm{~g}$ / liter water for root dipping. They were applied at four 
different stages of crop i.e. before sowing (Seed treatment), before transplanting (Seedling root dipping), at tillering stage (Spraying) and at symptoms initiation stage (Spraying). Tricoderma herzianum and Pseudomonous fluorescens both were talc based formulation and their strength were $4.66 \times 10^{7}$ and $6.00 \times 10^{6}$ respectively.

Total $300 \mathrm{~g}$ seeds of rice, variety Pusa basmati-1 were treated with eitherValidamycin @ 0.1 per cent, or Pseudomonas fluorescens@ @ $\mathrm{g} \mathrm{Kg}^{-1}$ seed or Trichodermaharzianum @ 4g Kg-1 seed as per treatment need.The seed treatment was done by seed dipping method in case of validamycin and by slurry method in case of antagonists, at least one day in advance of sowing. The seeds dipped into plain water only served as check. Rice nursery was raised as per standard method. Twenty five day old seedlings were taken for transplanting. For seedling root dipping, uprooted seedlings were thoroughly washed with running water to wash out clay particles and cleaning of root lets. Washed seedlings were dipped in the desired concentration of either Validamycin or Pseudomonas fluorescens or Trichoderma harzianum as per treatment need, for at least 20 minutes. Seedlings dipped into plain water only, served as check. The seedlings were transplanted in well puddled plots of $2 \times 1 \mathrm{~m}^{2}$ size with row to row spacing of $20 \mathrm{~cm}$ and plant to plant spacing of $10 \mathrm{~cm}$ for respective treatments. The fertilizers, NPK and $\mathrm{Zn}$ were applied at the rate of $120,75,60$ and $5 \mathrm{~kg} / \mathrm{ha}$. Out of total amount of mentioned fertilizers, $60 \mathrm{~kg}$ nitrogen in the form of urea, and complete dosages of phosphorous, potassium and zinc in the form of single super phosphate, muriate of potash and zinc sulphate, respectively were applied as basal dosages and remaining amount of nitrogen were applied as top dressing in two split dosages at the time of tillering and boot leaf stage.

The crop was sprayed either once or twice with the Validamycin at tillering and symptoms initiation or both the stages as per treatments need. The spray operation was done during the evening with the help of Knap sack sprayer. The crop was sprayed till run off. In control plot (Untreated control) only plain water was sprayed. One more treatment was maintained by only one spraying of Carbendazim at the rate of $0.1 \%$ at the time of symptoms initiation which served as standard control. Application of Carbendazim is already a recommended practice for sheath blight management and results of other operations during this study for sheath blight management had to be compared with it as well as untreated check i.e. plain water. The disease incidence was recorded by counting total number of plants and number of plants infected with sheath blight in a particular plot representing specific treatment. The disease severity was recorded with the help of randomly selected five hills in a plot. The selected hills were tagged for identification. These tagged hills were taken for recording observations on disease severity with the help of 0 to 9 rating scales (IRRI, 1988) throughout the investigation period. Experiments were conducted for two years i.e. 2004 and 2005 and crop was shown in the month of July (Showing of seeds on 01-07-04 and 0107-05 and transplanting on 25-07-04 and 25-07-05) and harvested in the month of November and threshed manually. The grain weight was recorded from individual plot and per cent yield increase was also recorded. It is worthwhile to mention that in Kumarganj (Faizabad) May and June have very high temperature $\left[\left(29^{\circ} \mathrm{C}\right.\right.$ to $\left.32^{\circ} \mathrm{C}\right)$ mean temperature] and December, January are coolest months with mean temperature of 13 to $15^{\circ} \mathrm{C}$. The rainy season receive medium to high rains during July to September.

\section{RESULTS AND DISCUSSION}

Effect on disease incidence: Based on disease incidence $(73.34 \%$ ) recorded in un-protected crop ( where only plain water was applied) and the crops protected with various combinations of antagonists and Validamycin at different crop growth stages (Table-1), it was found that single spraying of Carbendazim at symptoms initiation stage, resulted in highest reduction $(81.36 \%)$ in disease incidence, followed by the crop where Trichoderma harzianum was applied as seed treatment and Pseudomonas fluorescens was applied as seeding root dip and two spraying of Validamycin i.e. at tillering and symptoms initiation stage $\left(\mathrm{T}_{10}\right)$, where $69.10 \%$ reduction was recorded. However when sequence of application of Trichoderma harzianum and Pseudomonas fluorescens was altered i.e. Pseudomonas fluorescens was applied as seed treatment and Trichoderma harzianum was applied as seedling root dip, followed by two spraying of Validamycin i.e. at tillering and symptoms initiation stage $\left(\mathrm{T}_{11}\right)$, it resulted in $62.72 \%$ reduction in disease incidence.

When Pseudomonas fluorescens was applied as seed treatment and the same nursery was given seedling root dip treatment with Validamycin $\left(\mathrm{T}_{5}\right)$ it resulted in $50 \%$ reduction in disease incidence. Validamycin application as seedling root dip either alone $\left(\mathrm{T}_{2}\right)$ or when prior seed treatment was given with Trichoderma harzianum $\left(\mathrm{T}_{4}\right)$, both treatments resulted in similar level of reduction in disease incidence i.e. $47.27 \%$. Slightly lower level of reduction in disease incidence $(46.35 \%)$ was noticed when rice seeds were treated with Pseudomonas fluorescens and seedling roots were dipped in Trichoderma harzianum and crop was sprayed with Validamycin at symptoms initiation stage $\left(\mathrm{T}_{8}\right)$. Reduction in disease incidence was 43.18 per cent, when Trichoderma harzianum was applied as seed treatment and roots of such seedlings were dipped with 
Pseudomonas fluorescens and Validamycin was sprayed in the same crop at symptoms initiation stage $\left(\mathrm{T}_{9}\right)$. Seedling root dip with Pseudomonas fluorescens, followed by Validamycin spraying at symptoms initiation stage $\left(T_{7}\right)$ resulted in $41.81 \%$ reduction in sheath blight incidence. Single spraying of Validamycin at symptoms initiation stage $\left(\mathrm{T}_{3}\right)$ resulted in $29.54 \%$ reduction of disease incidence, whereas, single spraying of Validamycin in the crop where seedlings roots were dipped with Trichoderma harzianum $\left(\mathrm{T}_{6}\right)$, resulted in $30.91 \%$ reduction in sheath blight incidence. Single application of Validamycin as seed treatment $\left(\mathrm{T}_{1}\right)$, resulted in only $9.09 \%$ reduction in sheath blight incidence.

Effect on severity of disease : From the data given in Table-1, it is evident that highest disease severity i.e. $74.59 \%$ was noticed in check plot $\left(\mathrm{T}_{12}\right)$ (plain water was sprayed), whereas the lowest disease severity (12.59\%) was noticed when only one spraying of Carbendazim $\left(\mathrm{T}_{13}\right)$ was done and also when Trichoderma harzianum was applied as seed treatment and Pseudomonas fluorescens was applied as seedling root dip and Validamycin, was sprayed twice i.e. at tillering and symptoms initiation stage $\left(\mathrm{T}_{10}\right)$. When sequence of application was altered i.e. Pseudomonas fluorescens was applied as seed treatment and Trichoderma harzianum was applied as seedling root dip and Validamycin was sprayed twice i.e. at tillering and symptoms initiation stage $\left(\mathrm{T}_{11}\right)$, it resulted in $81.19 \%$ reduction in severity of disease which was at par with $\mathrm{T}_{10}$ and $\mathrm{T}_{12}$. Seed treatment with Trichoderma harzianum and seedling root dip with Pseudomonas fluorescens and Validamycin spraying at symptoms initiation stage $\left(\mathrm{T}_{9}\right)$, resulted in $22.96 \%$ severity (69.30\% reduction) which was at par with the sheath blight severity (25.92\% and $65.35 \%$ reduction) observed in the crop where seedling roots were dipped in Pseudomonas fluorescens and Validamycin was sprayed at symptoms initiation stage $\left(\mathrm{T}_{7}\right)$, it was further at par with disease severity ( $27.40 \%$ and $63.37 \%$ reduction) noticed in the crop where Pseudomonas fluorescens was applied as seed treatment and Trichoderma harzianum was applied as seedling root dipping and Validamycin was sprayed at symptoms initiation stage $\left(\mathrm{T}_{8}\right)$. Single spraying of Validamycin at symptoms initiation stage either alone $\left(\mathrm{T}_{3}\right)$ or in the crops raised from the seedlings where roots were dipped in Trichoderma harzianum $\left(\mathrm{T}_{6}\right)$ resulted in statistically similar level of disease severity i.e. $34.81 \%$ and $33.33 \%$, respectively with $53.46 \%$ and $55.44 \%$ reduction. Seed treatment with Pseudomonas fluorescens and seedling root dip in Validamycin $\left(\mathrm{T}_{5}\right)$ resulted in $37.77 \%$ disease severity with $49.59 \%$ reduction. It was at par with the disease severity in the crop, where Validamycin was applied at symptoms initiation stage $\left(\mathrm{T}_{3}\right)$. When Trichoderma harzianum was applied as seed treatment and Validamycin was applied as seedling rot
$\operatorname{dip}\left(\mathrm{T}_{4}\right)$, it resulted in $40.73 \%$ disease severity and $45.55 \%$ reduction in severity. Statistically similar level of disease severity i.e. $43.77 \%$ and $42.22 \%$ were recorded in the crop where Validamycin was applied either as seed treatment $\left(\mathrm{T}_{1}\right)$ or seedling root dipping $\left(\mathrm{T}_{2}\right)$. Reduction in disease severity in these two treatments were $41.48 \%$ and $43.56 \%$, respectively.

Effect on the yield of crop: Highest yield $(820 \mathrm{~g} / \mathrm{plot}$ and $62.92 \%$ increase) was obtained in the crop sprayed with Carbendazim $\left(\mathrm{T}_{13}\right)$. It was at par with average yield $(810.67 \mathrm{gm} /$ plot and $62.49 \%$ inhancement $)$ obtained in the crop where Trichoderma harzianum was applied as seed treatment and seedling roots were dipped with Pseudomonas fluorescens, followed by two spraying of Validamycin at tillering and symptoms initiation stage $\left(\mathrm{T}_{10}\right)$. When sequence of application was altered i.e. Pseudomonas fluorescens was applied as seed treatment and seedling roots were dipped in Trichoderma harzianum followed by two spraying of Validamycin i.e. at tillering and symptoms initiation stage $\left(\mathrm{T}_{11}\right)$, it resulted in $792.33 \mathrm{~g} /$ plot yield with $61.63 \%$ yield increase. Seed treatment with Trichoderma harzianum and seedling root dipping with Pseudomonas fluorescens followed by spraying of Validamycin at symptoms initiation stage $\left(\mathrm{T}_{9}\right)$ resulted in an average yield of $675.67 \mathrm{~g} /$ plot with an increase of $54.55 \%$. Seedlings root dipping in Pseudomonas fluorescens and one spraying of Validamycin at symptoms initiation stage $\left(\mathrm{T}_{7}\right)$, resulted in an average yield of $647.67 \mathrm{~g} / \mathrm{plot}$ which, was significantly less than the yield mentioned earlier in respective treatments. Seed treatment with Pseudomonas fluorescens and seedling root dipping in Trichoderma harzianum followed by one spraying of Validamycin at symptoms initiation stage $\left(\mathrm{T}_{8}\right)$ resulted in an average yield of $633.33 \mathrm{~g} / \mathrm{plot}$ with an increase of $51.99 \%$. Seedling root dipping in Trichoderma harzianum and one spraying of Validamycin at symptoms initiation stage $\left(\mathrm{T}_{6}\right)$ resulted in an average yield of $584.33 \mathrm{~g} / \mathrm{plot}$, which was significantly less than the yield obtained in treatments mentioned earlier, but it was at par with yield obtained (582 g/ plot), due to only one spraying of Validamycin at symptoms initiation stage $\left(\mathrm{T}_{3}\right)$. Remaining four treatments, i.e. $\mathrm{T}_{1}$, $\mathrm{T}_{2}, \mathrm{~T}_{4}$ and $\mathrm{T}_{5}$ resulted in an average yield which were at par.

Upmanyu et al., (2002), reported that foliar spray of Carbendazim @ 0.1\% and Tebuconazole @ 0.05\% were most effective in reducing sheath blight severity caused by Rhizoctonia solani Kûhn. Singh and singh (2009) reported that application of Carbendazim @ 0.1\% at symptoms initiation stage was highly effective in reducing sheath blight incidence and severity as well as enhancing the rice yield. However four application of Validamycin@0.1\% at four crop stages i.e.seed, seedling, tillering and symptoms initiation stage was 
Table 1. Effect of combinations of antagonists and chemical (Validamycin 3L) on sheath blight incidence, severity and grain yield of rice.

\begin{tabular}{|c|c|c|c|c|c|c|c|c|}
\hline \multirow{2}{*}{$\begin{array}{l}\text { S. } \\
\text { No. } \\
1 .\end{array}$} & \multicolumn{2}{|c|}{ Treatment's details } & \multirow{2}{*}{$\begin{array}{c}\begin{array}{c}\text { Disease } \\
\text { incidence (\%) }\end{array} \\
66.67(54.79)\end{array}$} & \multirow{2}{*}{$\begin{array}{c}\begin{array}{c}\text { Per cent } \\
\text { reduction in } \\
\text { disease incidence }\end{array} \\
9.09 \%\end{array}$} & \multirow{2}{*}{$\begin{array}{c}\begin{array}{c}\text { Disease severity } \\
(\%)\end{array} \\
43.77(41.38)\end{array}$} & \multirow{2}{*}{$\begin{array}{c}\begin{array}{c}\text { Per cent } \\
\text { reduction in } \\
\text { disease severity }\end{array} \\
41.48\end{array}$} & \multirow{2}{*}{\multicolumn{2}{|c|}{$\begin{array}{c}\begin{array}{c}\text { Average yield } \\
\text { (g/ plot) }\end{array} \\
545.00\end{array}$}} \\
\hline & $\mathrm{T}_{1}$ & Seed treatment with Validamycin $3 \mathrm{~L}$ & & & & & & \\
\hline 2. & $\mathrm{~T}_{2}$ & Seedling root dip with Validamycin $3 \mathrm{~L}$ & 38.67 (38.44) & $47.27 \%$ & $42.22(40.52)$ & 43.56 & 546.00 & \\
\hline 3. & $\mathrm{~T}_{3}$ & Spray of Validamycin $3 \mathrm{~L}$ at symptom initiation stage & $51.67(45.96)$ & $29.54 \%$ & $34.81(36.14)$ & 53.46 & 582.00 & \\
\hline 4. & $\mathrm{~T}_{4}$ & $\begin{array}{l}\text { Seed treatment with Trichoderma harzianum + seedling root dip } \\
\text { with Validamycin } 3 \mathrm{~L}\end{array}$ & 38.67 (38.43) & $47.27 \%$ & $40.73(39.66)$ & 45.55 & 548.33 & \\
\hline 5. & $\mathrm{~T}_{5}$ & $\begin{array}{l}\text { Seed treatment with Pseudomonas fluorescence }+ \text { seedling root } \\
\text { dip with Validamycin } 3 \mathrm{~L}\end{array}$ & $36.67(37.25)$ & $50 \%$ & $37.77(37.92)$ & 49.51 & 552.33 & \\
\hline 6. & $\mathrm{~T}_{6}$ & $\begin{array}{l}\text { Seedling root dip with Trichoderma harzianum + spray of } \\
\text { Validamycin } 3 \mathrm{~L} \text { at symptom initiation }\end{array}$ & $50.67(45.38)$ & 30.91 & $33.33(35.26)$ & 55.44 & 584.33 & \\
\hline 7. & $\mathrm{~T}_{7}$ & $\begin{array}{l}\text { Seedling root dip with Pseudomonas fluorescence }+ \text { spray of } \\
\text { Validamycin } 3 \mathrm{~L} \text { at symptom initiation stage }\end{array}$ & 42.67 (40.78) & 41.81 & $25.92(30.59)$ & 65.35 & 647.67 & \\
\hline 8. & $\mathrm{~T}_{8}$ & $\begin{array}{l}\text { Seed treatment with Pseudomonas fluorescence + seedling root } \\
\text { dip with Trichoderma harzianum + spray of Validamycin } 3 \mathrm{~L} \text { at } \\
\text { symptom initiation stage }\end{array}$ & $39.34(38.83)$ & 46.35 & $27.40(31.55)$ & 63.37 & 633.33 & \\
\hline 9. & $\mathrm{~T}_{9}$ & $\begin{array}{l}\text { Seed treatment with Trichoderma harzianum + seedling root dip } \\
\text { with Pseudomonas fluorescence + spray of Validamycin } 3 \mathrm{~L} \text { at } \\
\text { symptom initiation stage }\end{array}$ & $41.67(40.20)$ & 43.18 & $22.96(28.61)$ & 69.30 & 675.67 & \\
\hline 10. & $\mathrm{~T}_{10}$ & $\begin{array}{l}\text { Seed treatment with Trichoderma harzianum + seedling root dip } \\
\text { with Pseudomonas fluorescence }+ \text { spray of Validamycin } 3 \mathrm{~L} \text { at } \\
\text { tillering stage }+ \text { spray of Validamycin } 3 \mathrm{~L} \text { at symptom initiation } \\
\text { stage }\end{array}$ & $22.66(28.41)$ & 69.10 & $12.59(20.72)$ & 83.17 & 810.67 & \\
\hline 11. & $\mathrm{~T}_{11}$ & $\begin{array}{l}\text { Seed treatment with Pseudomonas fluorescence }+ \text { seedling root } \\
\text { dip with Trichoderma harzianum }+ \text { spray of Validamycin } 3 \mathrm{~L} \text { at } \\
\text { tillering stage }+ \text { spray of Validamycin } 3 \mathrm{~L} \text { at symptom initiation } \\
\text { stage }\end{array}$ & $27.34(31.52)$ & 62.72 & $14.07(21.97)$ & 81.19 & 792.33 & \\
\hline 12. & $\mathrm{~T}_{12}$ & Untreated (Check) & 73.34 (58.93) & - & $74.59(59.89)$ & - & 304.00 & \\
\hline 13. & $\mathrm{~T}_{13}$ & Standard control (Carbendazim @ 0.1\%) & $13.67(21.66)$ & 81.36 & $12.59(20.72)$ & 83.17 & 820.00 & \\
\hline & CD & & 3.56 & & 2.66 & & 12 & \\
\hline
\end{tabular}


also found to be equally effective in reducing disease incidence, disease severity and yield enhancement. Khan and Sinha (2006) reported that the maximum reduction in deases servity and incidence were recorded with FYM + Trichoderma herzianum. Whereas neem cake + Trichoderma herzianum and Dhaincha + Trichoderma herzianum were next in order of effectivity.

Reduction in disease incidence and severity may be one of the possible reasons for maximum enhancement of grain yield due to different treatment. In the present investigation highest grain yield was recorded due to Carbendazim application which resulted in lowest disease severity. In rest of the treatments the increase in grain yield was in the same proportion in which disease severity was reduced. It was also interesting to note the efficacy of Trichoderma herzianum and Pseudomonas flourescens as seed treatment or seedling rootdip. This may be due to induced systemic resistance in rice due to these two bioagents.

\section{REFERENCES}

International Rice Research Institute,(1988). Annual Report for $1987,46-49,145-148$.

Khan, Asaraf Ali and Sinha A.P.(2006). Integration of fungal antagonists and organic amendments for the control of rice sheath blight. Indian Phytopath. 59 (3) 363-365.

Miyake, I. (1910). Studien uber die Pilze der Reispflanze in Japan. Journal of the College of Agriculture, Imperial University of Tokyo. $2: 237-276$.

Singh, Ramji and Singh Bhuneshwar (2009). Efficacy of validamycin at different crop stages against sheath blight of rice.Indian Phytopath. 62 (3) 319-323

Upmanyu, S.; Gupta, S.K. and Shyam, K.R. (2002). Innovating approaches for the management of root rot and web blight (R. solani) of French bean. J. Mycol. Plantl. Pathol. 32 (3) : 317-331. 